\title{
O BLOQUEIO DO SÂNDI VOCÁLICO EM PB E EM PE: EVIDÊNCIAS DA FRASE FONOLÓGICA \\ - Luciani Tenani -
}

RESUMO: In this paper, the contexts that block vowel merger and vowel deletion in Brazilian Portuguese and European Portuguese are analysed. It aims at identifying differences and similarities between $B P$ and $E P$, which may be related to their rhythmic and prosodic organization. Therefore, speech data were collected for BP following the methodology employed by the research done by Frota (1998) for EP. Comparing BP and EP, we found that in both of them there are (i) rhythmic restrictions that block ill-formed rhythmic configuration at phrase phonological level; (ii) a directional head-effect which is related to the restriction that preserves the prominence of rightmost stress within the phonological phrase; (iii) active restrictions that depend on the type of phonological process and of prosodic structure in which sandhi contexts are found. What makes BP differ from EP is the fact that vowel merger and vowel deletion are blocked depending on V1/V2 distinction and prosodic prominence.

PALAVRAS-CHAVE: Sândi Vocálico. Domínios prosódicos. Acento. Língua Portuguesa.

\section{INTRODUÇÃO}

Neste texto, voltamos nossa atenção aos contextos acentuais que bloqueiam os processos de sândi vocálico em Português Brasileiro (PB) e em Português Europeu (PE). São estudados os contextos em que uma das vogais da seqüência vocálica é acentuada, seja essa seqüência de vogais iguais ou diferentes. ${ }^{1}$

O objetivo deste trabalho é identificar semelhanças e diferenças entre o PB e o PE quanto aos processos de degeminação (DG) e elisão (EL) e, mais especificamente, busca-se comparar PB e PE quanto às suas organizações rítmica e prosódica. A fim de realizar essa comparação, tomamos como ponto de partida as descobertas feitas por Frota (1998) para o PE e adotamos a mesma metodologia de investigação para fazer a coleta de dados do PB, a ser descrita na seção 3. A discussão dos resultados obtidos para o PB e a comparação com o PE é feita na seção 4. Na última seção, é feita uma sistematização das semelhanças e diferenças encontradas. A seguir, são apresentadas as características do sândi vocálico no PB que embasam este trabalho.

\section{SOBRE O SÂNDI VOCÁLICO EM PORTUGUÊS BRASILEIRO}

Ao caracterizar o sândi vocálico, Bisol (1993) traça um panorama completo das possibilidades de aplicação e bloqueio da degeminação, da elisão e da ditongação. Resumidamente, pode-se afirmar que é o acento o fator que gera os contextos de bloqueio do sândi vocálico, pois: (i) quando ambas as vogais são tônicas, nenhum dos três processos se implementam, como exemplifica (1.1); (ii) quando a primeira vogal é tônica, como em (1.2), a elisão não ocorre, como exemplifica (1.2.ii); (iii) quando a segunda vogal é tônica, como em (1.3), nem a elisão nem a degeminação ocorrem, como exemplificam (1.3.i) e (1.3.ii). ${ }^{2}$

(1)

\begin{tabular}{|c|c|}
\hline 1.i. Vi isso & ['vi 'isu] \\
\hline 1.ii. Dá isso & ['da 'isu] \\
\hline 1.iii. Vi este & ['vi 'est $\left.\int \mathrm{I}\right]$ \\
\hline 2.i. Babá amorosa & [ba'bamo'roza] \\
\hline 2.ii. Babá elegante & [ba'baelegว̃t $\mathrm{I}$ ] \\
\hline 2.iii. Bebê urinado & [be'bewri'nadv] \\
\hline 3.i. Como uvas & ['komw'uvas] \\
\hline 3.ii. Coma uvas & ['koma'uvas] \\
\hline 3.iii. Come uvas & ['komi'uvas] \\
\hline
\end{tabular}

Luciani Tenani é professora do Departamento de Estudos Lingüísticos e Literários da UNESP/São José do Rio Preto. 


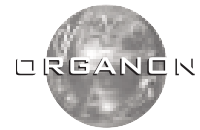

A partir da descrição de Bisol (1993), consideramos, neste trabalho, os contextos de bloqueio de sândi que são motivados pela presença do acento e também controlamos a fronteira prosódica tomando por base a argumentação de Abaurre (1996). Essa pesquisadora retoma do trabalho de Bisol (1993) os contextos em que a segunda vogal é acentuada tanto para a EL, em (2.1), quanto para a DG, em (2.2), e observa que, em ambos os casos, o ambiente em questão é o mesmo: a segunda vogal da seqüencia é portadora de acento nuclear no nível da frase fonológica. Evidências dessa afirmação podem ser observadas quando comparados (2.i), onde os processos se aplicam, com (2.ii), onde os processos são bloqueados.

(2)

1.i. [ [Ele] $\phi$ [compra] $\phi$ [uvvas CAras] $\phi] I \Rightarrow$ Ele cómpr[u]vas caras 1.ii. [ [Ele] $\phi$ [compra] $\phi[\underline{u v a s}] \phi] I \Rightarrow *$ Ele compr[ú]vas

2.i. [ [Eu] $\phi[$ compro] $\phi$ [uvas sEMpre] $\phi] I \Rightarrow$ Eu cómpr[u]vas sempre 2.ii. [ [Eu] $\phi[$ Compro] $\phi[\underline{u v a s}] \phi] I \Rightarrow *$ Eu compr[ú] vas.

Para Abaurre (1996: 45), tais fatos indicam que a análise feita por Bisol (1993), "embora descritivamente adequada e perfeitamente coerente com a direção bottom-up de atribuição de acento e construção da grade métrica por ela assumida, não parece realmente explicar por que a elisão e a degeminação se tornam possíveis quando o acento primário de palavra é, em suas palavras, 'enfraquecido por razões prosódicas e rítmicas".

Ao levar em conta dados como os apresentados em (2), a autora afirma que "o bloqueio a esses processos ocorre quando [o] acento primário de palavra, atribuído no componente lexical, é também interpretado, póslexicalmente, como acento frasal, portador de informação sintática, dentro de uma hierarquia de proeminências prosódicas sintaticamente motivadas" (Abaurre, 1996: 46). Desse modo, a EL ocorre em (2.i), mas é bloqueada em (2.ii). Esse fato está relacionado, segundo a pesquisadora, ao algoritmo de formação da frase fonológica (doravante, $\phi$ ) na medida em que a proeminência relativa de $\phi$ sinaliza a direção da recursividade sintática nas línguas naturais (o que é, por definição, um parâmetro sintático). Como o português é uma língua de recursividade à direita (cf. Cinque, 1993), ao acento mais à direita será atribuído o valor forte, assim, o acento de $\phi$ mais à direita tem relação com a recursividade sintática.

Recorrendo ao trabalho de Nespor (1994), Abaurre traz informações sobre experimentos em aquisição da linguagem que parecem confirmar a saliência prosódico-sintática do acento de frase fonológica e sua relevância no estabelecimento da interface entre os módulos fonológico e sintático. Também Hayes (1991) afirma que a atribuição de acento no nível frasal exibe diferenças marcantes com relação à atribuição do acento de palavra, as quais parecem corroborar uma interpretação do acento frasal como tendo uma natureza não puramente fonológica. Os resultados desses trabalhos são tomados como a base para a hipótese formulada por Abaurre (1996), segundo a qual "a implementação dos processos fonológicos, como o sândi externo no português, pode ser (em parte) regulada pelo acento frasal" (p. 47).

Abaurre (1996) ainda fundamenta o fato de o acento frasal estar relacionado ao padrão de proeminências rítmicas nas afirmações feitas por Selkirk (1984). Essa pesquisadora vincula explicitamente os possíveis padrões de proeminências rítmicas dos enunciados às suas propriedades entoacionais ao citar Selkirk (1984):

"os elementos tonais acentualmente relevantes (pitch accents) são atribuídos às palavras na estrutura superficial independentemente dos padrões de acento frasal, e os padrões frasais são parcialmente definidos como uma função da localização das palavras que, na sentença, são portadoras do pitch accent." (ABAURRE, 1996: 47).

Em outras palavras, os padrões rítmicos são determinados pelos padrões entoacionais, e esta relação pode definir, segundo Selkirk (1984), o lugar da proeminência relativa de constituintes sintáticos, através de sua delimitação prosódica.

Dessas considerações, torna-se evidente a importância do acento frasal e do seu estatuto prosódico, pois a este acento estão associadas informações não apenas de natureza rítmica, mas também entoacional e, por fim, sintáticas. Como o acento frasal é aquele que bloqueia os processos de sândi em PB, Abaurre (1996) interpreta esse fato como um conflito de natureza 'teleológica'. 
"Esse conflito envolve, por um lado, princípios de boa-formação das seqüências fonológicas que se manifestam através da tendência à otimização da cadeia silábica $[\ldots]$; envolve ainda, por outro lado, a tendência a preservar a estrutura portadora da informação sintática relevante" ( $\mathrm{p}$. 48). Nesse embate, a análise dos dados da DG e da EL indicia que a tendência para se preservar a estrutura portadora de informação sintática prevalece sobre a tendência à otimização silábica no nível da frase fonológica. Nessa afirmação de Abaurre está implícita outra a respeito da interface dos módulos da gramática: a sintaxe tem prevalência sobre a fonologia.

Abaurre conclui seu texto observando que Bisol (1996a) não deixa de perceber que o acento de frase fonológica está envolvido no bloqueio da DG e da EL, porém deixa de formalizar o fato considerado relevante que é a referência à proeminência de nível hierarquicamente superior ao acento lexical, ou seja, o acento da frase fonológica. Dessa maneira, Abaurre (1996) argumenta que é a frase fonológica o domínio prosódico de aplicação e bloqueio dos fenômenos de sândi e, desse modo, o acento deste domínio deve ser mantido, o que mostra que, em PB, a necessidade de se preservarem ao máximo os contextos estruturais portadores de informação sintática prevalece sobre a otimização no nível silábico.

Posto que a DG e a EL são bloqueadas pelo elemento mais proeminente de $\phi$, tem-se aí uma evidência da relevância desse domínio para o PB. Avançamos, porém, neste trabalho ao colocar em cena o choque de acentos. Por meio de experimento, a ser apresentado na próxima seção, controlamos a distância entre os acentos das palavras sujeitas ao sândi e a relação de proeminência entre os acentos no domínio de $\phi$. O controle dessas variáveis se justifica em função dos fatos relativos ao choque de acentos em PB.

A literatura que trata do choque de acentos, especialmente os trabalhos que se inserem no quadro teórico da Fonologia Métrica, aponta a distância entre os acentos e a estrutura prosódica como dois fatores que estão relacionados às restrições rítmicas identificadas nas línguas em geral. ${ }^{3}$

As configurações das grades métricas geradas desse mapeamento nem sempre são bemformadas. Em alguns casos, as proeminências estão tão próximas que resultam em um choque de acentos (stress clash); em outros casos, as proeminências estão tão longe umas das outras que resultam em 'lapsos' de acentos (stress lapses). Para solucionar essas configurações de modo a implementar uma seqüência com uma maior alternância rítmica, regras de reajustes são aplicadas. As estratégias de resolução de choque de acentos e o nível em que esse choque é avaliado como uma configuração malformada diferem entre as línguas. Além dessas duas variáveis, a direção (direita/esquerda) em que operam os ajustes rítmicos também varia entre as línguas.

Em PB, o trabalho sobre choque de acentos de Abousalh (1997) mostra que a resolução da colisão acentual opera dentro do domínio da frase fonológica por meio de uma estratégia de retração à esquerda do acento. Já o choque de acentos entre $\phi_{s}$ parece não ser resolvido por essa mesma estratégia, segundo a pesquisadora. Esse fato pode ser indício de que provavelmente a língua deve dispor de algum outro mecanismo para resolver essa configuração rítmica. A autora aborda como estratégia de resolução dos choques apenas 'o apagamento/movimento de acento, a inserção de pausas e de contornos entoacionais' (p. 19), pois opta por trabalhar 'somente com uma transcrição orientada por critérios lingüísticos' (p. 18), isto é, a análise é baseada em uma transcrição auditiva de dados não obtidos em laboratório. Portanto, não são investigadas outras estratégias como a inserção de uma batida rítmica (beat insertion) entre os acentos ou os correlatos acústicos das estratégias empregadas em PB.

Também Sandalo \& Truckenbrodt (2002) tratam do choque de acentos em PB e tomam por base julgamentos dos falantes sobre a possibilidade de retração de acentos em sentenças lidas (como enunciados de jornal, por exemplo), mas também não é aventada a possibilidade de haver outras estratégias de resolução de choque acentual. O bloqueio dessa regra de retração de acentos está submetido, segundo esses autores, a certas restrições relacionadas ao estabelecimento das fronteiras de $\phi .{ }^{4}$

Portanto, pode-se afirmar que não há dúvidas da relevância de $\phi$ quer para o bloqueio da DG e da EL, quer para o bloqueio da resolução de choque de acentos. Neste texto, buscamos verificar a interação entre o bloqueio desses processos de sândi e as estratégias de resolução de choque de acentos. 


\section{EXPERIMENTO}

A fim de alcançar nosso objetivo, foi feito um experimento em que é controlada a tonicidade das vogais sujeitas ao sândi de modo a relacionar essa tonicidade à saliência prosódica de $\phi$. Também consideramos a fronteira de $I$, pois essa fronteira é crucial para o PE. Ou seja, foram elaborados contextos em que o acento de palavra é também interpretado como acento frasal, o qual se manifesta de modo mais evidente por meio da variação de F0, conforme a literatura sobre o acento em PB. Como nos interessa a comparação entre as duas variedades do Português, controlamos a fronteira de $I$ da mesma maneira que Frota (1998) o fez para o PE. Desse modo, foram elaboradas sentenças nas quais a localização das fronteiras de $\phi$ e de $I$ e os contextos de sândi foram sistematicamente variados. ${ }^{5}$ Abaixo, são dados alguns exemplos de sentenças do corpus, com indicação dos contextos de sândi (sublinhado), dos acentos (em caixa alta) e das fronteiras prosódicas relevantes.

(3)

1. [a aLuna Árabe] $\phi$ [enviou uma carta] $\phi$ [à cantora] $\phi$

2. [a a a una $] \phi[\underline{a} g \mathrm{ge} \phi[\mathrm{com}$ discrição] $\phi[\mathrm{em}$ público] $\phi$

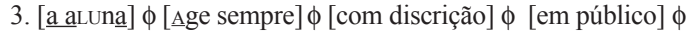

4. [a aluna,$] I$ [ávida por justiça,] $I$ [falou com a diretora.] $I$

Em todas as sentenças em (3), o artigo $a$ pertence ao mesmo $\phi$ do nome aluna e, por essa razão, espera-se a aplicação da DG, uma vez que, como já mostrado na seção anterior, $\phi$ é o domínio preferencial para aplicação de sândi externo (porque sempre ocorre a aplicação desse processo nesse domínio entre vogais átonas). ${ }^{6}$ Em (3.1), aluna árabe é formada por $\phi_{\mathrm{s}}$ passíveis de sofrerem reestruturação, conforme previsto pelo algoritmo desse domínio, constituindo-se, assim, em uma unidade fonológica pelo fato de árabe constituir um $\phi$ não-ramificado que é complemento da cabeça lexical X (no caso, aluna) do seu lado recursivo. Em (3.2), a relação é entre as fronteiras de $\phi$, sendo os dois $\phi_{\mathrm{s}}$ não-ramificados. Em (3.3), a relação prosódica relevante se dá entre um $\phi$ não-ramificado, formado por um nome em posição de sujeito (aluna), e outro $\phi$-ramificado, formado por um verbo e um advérbio (age sempre). Cabe observar que, pelo algoritmo de $\phi$, age sempre é mapeado em dois $\phi_{\mathrm{s}}$, a saber: [age] $\phi$ [sempre $] \phi$, que são passíveis de

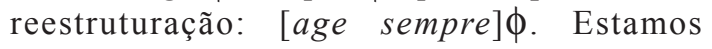

considerando, como também o fez Frota (1998) para o PE que a estrutura relevante é [age sempre $] \phi$. Finalmente em (3.4), a fronteira prosódica considerada é do domínio $I$. Nesse caso, é prevista a fronteira de $I$ entre aluna e ávida em razão de haver o mapeamento do parêntese 'ávida por justiça' como um único $I$, o que a delimita em relação à porção anterior e posterior da sentença em que é encaixada. ${ }^{7}$ Todas as fronteiras prosódicas consideradas são elencadas abaixo.

(4)

Tipo de estrutura prosódica

a. Mesmo $\phi$

b. $\phi+\phi$-não-ramificado

c. $\phi+\phi$-ramificado

d. I+I

Também foi controlada a tonicidade das vogais sujeitas ao sândi de modo a relacionar essa tonicidade à proeminência prosódica do domínio da frase fonológica. Com base nos trabalhos de Bisol (1992, 1993, 1996a,b, 2000) e de Abaurre (1996), constata-se que a tonicidade da segunda vogal é crucial, pois, é o acento dessa vogal que gera o bloqueio da DG e da EL quando esse for interpretado como acento de $\phi .{ }^{8}$ Dessa maneira, foram considerados contextos em que a segunda vogal é tônica $\left(\mathrm{v}+\mathrm{v}^{\prime}\right)$ tanto para a seqüência de /a+á/, como em (5.i), que permite observar o processo da DG, quanto para seqüência de /a+ú/, como em (5.ii), que caracteriza o contexto segmental da EL em PB.

(5)

1.i. [a aLuna $\underline{\text { árabe] }} \phi$ [enviou] $\phi$ [uma carta] $\phi$ [à cantora] $\phi$

1.ii. [a aLuna útil] $\phi$ [ganhou] $\phi$ [uma viagem] $\phi$ [de férias] $\phi$

2.i. [a aLuna $] \phi[\underline{A} g e] \phi[\mathrm{com}$ discrição] $\phi[\mathrm{em}$ público] $\phi$

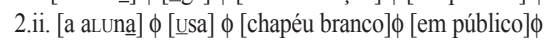

3.i. [a aLuna] $\phi$ [ $\underline{\text { gge sempre }]} \phi$ [com discrição] $\phi[\mathrm{em}$ público] $\phi$

3.ii. [a aLuna] $\phi$ [usa sEmpre] $\phi$ [chapéu branco] $\phi[\mathrm{em}$ público] $\phi$

4.i. [a aluna] $I$ [Ávida por justiça] $I$ [falou com a diretora] $I$

4.ii. [a aLuna] $][$ [Uttil mas desorganizada] $I$ [encantou o público brasileiro] $I$

Posto que nosso objetivo principal é a comparação da estrutura prosódica do PB com a de $\mathrm{PE}$, optamos por levar em conta também o contexto em que o acento recai na primeira sílaba da seqüência da DG ou da EL. Em PE, diferentemente do PB, o sândi vocálico também é bloqueado quando a primeira vogal é acentuada, como em casos como (6). Considerando as seqüências /á+a/ (cf. 6.i) e / á + u/ (cf. 6.ii) e as diferentes estruturas prosódicas 
(cf. 4), busca-se obter dados comparáveis com os analisados para o PE.

(6)

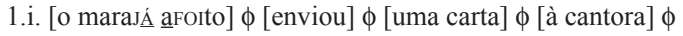

1.ii. [o marajá humiLde] $\phi$ [recebeu flores] $\phi$

2.i. [o maraj俩] $\phi$ [äceIta] $\phi$ [o papel] $\phi$ [de bandido] $\phi$

2.ii. [o maras $\underline{A}] \phi$ [ussava] $\phi$ [roupa branca] $\phi$

3.i. [o maraj $\underline{\underline{A}}] \phi$ [ạpenas enviou] $\phi$ [flores] $\phi$ [à bailarina $] \phi$

3.ii. [o maras $\underline{\hat{A}}] \phi$ [ussava sempre] $\phi$ [roupa clara] $\phi$

4.i. [o maraj白] $I$ [äPós o confLito] $I$ [repousou em seu quarto] $I$

4.ii. [o marajé $] I$ [hümiLde como a cantora] $I$ [recebeu os presentes] $I$

Finalmente, o último contexto analisado que envolve choque de acentos é a seqüência em que ambas as vogais são acentuadas, como ilustra (7). Nas duas variedades do Português, o sândi vocálico é bloqueado nesse contexto acentual. No entanto, em PB não se investigou por meio de qual estratégia é solucionado esse choque de acentos quando envolve um contexto de sândi vocálico nas diferentes estruturas prosódicas (cf. 4). Através da análise dos contextos exemplificados em (7) se quer comparar as estratégias de resolução de choque de acentos em PB e em PE, quando o contexto segmental envolve um processo de sândi vocálico em diferentes estruturas prosódicas.

(7)

1. [o maraJ $\underline{\underline{A}} \underline{\operatorname{A} r a b e}] \phi$ [apresentou] $\phi$ [bons resultados] $\phi$

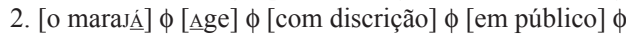

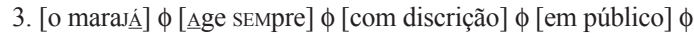

4. [o maraj̇ $]$ [ [Ágil como um raio] $I$ [encantou o público brasileiro] $I$

Ainda relacionada à tonicidade das vogais sujeitas ao sândi, foi sistematicamente controlada a distância entre os acentos das palavras sujeitas ao processo com o objetivo de verificar se o processo é bloqueado apenas quando sua aplicação gera choque de acentos, como em (8.i). Essa distância foi considerada, como o fez Frota (1998) para o PE, em termos de número de sílabas: uma ou duas sílabas entre os acentos primários. Ao ser controlada a distância entre os acentos, busca-se avaliar se há relação entre bloqueio/aplicação de sândi e a configuração métrica obtida. A partir das variáveis relacionadas ao acento das vogais foram elaboradas seqüências em que: (i) a distância entre os acentos é ora de uma ora de duas sílabas átonas (respectivamente, 8.1 versus 8.ii); (ii) ora a primeira vogal candidata ao sândi é átona e a segunda tônica (cf. 8.1 e 8.3 ), ora a primeira vogal candidata ao sândi é tônica e a segunda átona (cf. 8.2 e 8.4).
(8)

1.i. [a aLuna Árabe] $\phi$

1.ii. [a astróloga $\underline{A}$ rabe] $\phi$

2.i. [o marajÁ aFoIto] $\phi$

2.ii. [o marajÁ africAno] $\phi$

3.i. [a aLuna] $] \phi[\underline{\text { Age }}] \phi$

3.ii. [a astróloga $] \phi[\underline{\text { Age }}] \phi$

4.i. [o marajá $] \phi$ [aceita] $\phi$

4.ii. [o marajá $] \phi[\underline{a}$ ceitou $] \phi$

Em resumo, no primeiro conjunto de estruturas elaboradas, as variáveis 'tonicidade das vogais' e 'distância entre os acentos' foram controladas de modo a assegurar a relação entre essas variáveis e as fronteiras prosódicas consideradas (cf. 4). A interação dessas variáveis, somada aos dois contextos segmentais controlados, a saber $/ \mathrm{a}+\mathrm{a} / \mathrm{e} /$ $\mathrm{a}+\mathrm{u} /$, resulta em 32 estruturas ( 4 fronteiras prosódicas X 2 contextos segmentais X 2 posições de acento na seqüência $X 2$ contextos de distância entre os acentos). Essas variáveis são esquematicamente apresentadas no quadro abaixo.

Quadro 1. Variáveis controladas

\begin{tabular}{|l|l|}
\hline Estrutura prosódica & Mesmo $\phi$ \\
& $\phi+\phi$ não-ramificado \\
& $\phi+\phi$ ramificado \\
& $\mathrm{I}+\mathrm{I}$ \\
\hline Contexto segmental & $/ \mathrm{a}+\mathrm{a} /$ \\
& $/ \mathrm{a}+\mathrm{u} /$ \\
\hline Posição do acento & $\mathrm{V}+\mathrm{V}^{\prime}$ \\
na seqüência vocálica & $\mathrm{V}^{\prime}+\mathrm{V}$ \\
\hline Distância entre os acentos & 1 sílaba \\
& 2 sílabas \\
\hline
\end{tabular}

Noutro conjunto de estruturas, apenas é considerada a seqüência de vogais acentuadas /á+á/ em quatro diferentes fronteiras prosódicas, o que resultou em mais 4 estruturas (cf. 7).

As sentenças elaboradas a partir dessas estruturas foram lidas duas vezes por três informantes representantes do dialeto paulista, totalizando 216 ocorrências $(36 \times 2 \times 3)$.

\section{RESULTADOS E DISCUSSÃO}

Nesta seção, comparam-se os contextos em que uma das vogais da seqüência vocálica sujeita à DG ou à EL é acentuada com o objetivo de identificar semelhanças e diferenças entre o PB e o PE quanto às suas organizações rítmica e prosódica. Por meio do quadro abaixo, visualizam-se os contextos em que há o bloqueio da DG e da EL em função da estrutura prosódica e da tonicidade das vogais das seqüências consideradas. 
Quadro 2. Bloqueio do sândi vocálico em $P B$ e $P E^{9}$

\begin{tabular}{|c|c|c|c|c|c|c|c|c|}
\hline \multirow{3}{*}{$\frac{\mathrm{PB}}{\text { Estrutura prosódica }}$} & \multicolumn{4}{|c|}{ EL } & \multicolumn{4}{|c|}{ DG } \\
\hline & \multicolumn{2}{|c|}{$\cdot \mathrm{V} 1 \neq \mathrm{V} 2$} & \multicolumn{2}{|c|}{$\mathrm{V} 1 \neq \neq^{\prime} \mathrm{V} 2$} & \multicolumn{2}{|c|}{ 'V1=V2 } & \multicolumn{2}{|c|}{$\mathrm{V} 1={ }^{\prime} \mathrm{V} 2$} \\
\hline & $1 \sigma$ & $2 \sigma$ & $1 \sigma$ & $2 \sigma$ & $1 \sigma$ & $2 \sigma$ & $1 \sigma$ & $2 \sigma$ \\
\hline$\overline{\text { Mesmo } \phi}$ & EL/DT & EL/DT & EL/DT & EL/DT & DG & \begin{tabular}{|l|}
$\mathrm{DG}$ \\
\end{tabular} & DG & $\overline{D G}$ \\
\hline$\phi+\phi$ não-ramificado & EL/DT & EL/DT & EL/DT & $\mathbf{E L} / \mathrm{DT}$ & DG & $\mathrm{DG}$ & DG & DG \\
\hline$\phi+\phi$ ramificado & EL/DT & EL/DT & EL/DT & EL/DT & DG & $\mathrm{DG}$ & DG & DG \\
\hline $\mathrm{I}+\mathrm{I}$ & EL/DT & EL/DT & EL/DT & $\mathbf{E L} / \mathrm{DT}$ & DG & DG & DG & DG \\
\hline
\end{tabular}

\begin{tabular}{|c|c|c|c|c|c|c|c|c|}
\hline PE & \multicolumn{2}{|c|}{$\mathrm{V} 1 \neq \mathrm{V} 2$} & \multicolumn{2}{|c|}{$\mathrm{V} 1 \neq \mathrm{V} \mathrm{V} 2$} & \multicolumn{2}{|c|}{ 'V1=V2 } & \multicolumn{2}{|c|}{$\mathrm{V} 1={ }^{\prime} \mathrm{V} 2$} \\
\hline Estrut & $1 \sigma$ & $2 \sigma$ & $1 \sigma$ & $2 \sigma$ & $1 \sigma$ & $2 \sigma$ & $1 \sigma$ & $2 \sigma$ \\
\hline Tesr & $\mathrm{L} / \mathrm{D}$ & /DT & $\mathrm{LL} / \mathrm{DT}$ & EL/DT & DG & DG & DG & -8 \\
\hline & & & EL/DT & /DT & DG & DG & $\mathrm{DG}$ & DG \\
\hline & $\mathrm{L}$ & EL/DT & EL/DT & EL/DT & DG & DG & DG & $\mathrm{DG}$ \\
\hline & $\mathrm{L} / \mathrm{I}$ & L/DT & EL/DT & EL/DT & DG & DG & DC & DC \\
\hline
\end{tabular}

Onde: V1: primeira vogal da seqüência vocálica; V2: segunda vogal da seqüência vocálica; 'V: vogal acentuada; NEGRITO: o bloqueio dos processos; CAIXA ALTA: aplicação dos processos.

O primeiro ponto a destacar diz respeito ao contexto segmental que caracteriza a EL. Enquanto que em PE a EL é implementada quando /a/ é a segunda vogal, em PB esse processo somente ocorre quando /a/ for a primeira vogal da seqüência (cf. Bisol, 1993). Portanto, para se tratar do processo que consiste no apagamento da vogal /a/, faz-se necessário considerar cadeias segmentais em que essa vogal baixa não ocupa a mesma posição: em $\mathrm{PB}$, sempre será a primeira vogal, em PE, sempre a segunda vogal. ${ }^{10}$

Colocada essa primeira diferença entre PB e $\mathrm{PE}$, passamos a comparar os resultados para a seqüência em que uma das vogais é acentuada. Ao ser analisada a seqüência em que a primeira vogal é acentuada, verifica-se que (i) quando a seqüência for de vogais diferentes, a EL é bloqueada em ambas as variedades; (ii) quando a seqüência for de vogais iguais, a DG é sempre bloqueada em PE e é sempre implementada em todos os contextos prosódicos em $\mathrm{PB}$, como indicado no quadro (2).

Ao ser considerada a seqüência em que a segunda vogal é acentuada, encontram-se mais uma vez semelhanças e diferenças entre as duas variedades estudadas: (i) a EL é bloqueada nas duas variedades em um mesmo $\phi$ e entre $\phi_{\mathrm{s}}$ quando ambos não são ramificados, mas obtêm-se resultados diferentes, quando estão em jogo outras fronteiras prosódicas; (ii) a DG é bloqueada apenas em um mesmo $\phi$ e entre $\phi_{\mathrm{s}}$ em PB e sempre é bloqueada em PE, independentemente da fronteira prosódica em jogo.
Antes de avançarmos na análise das diferenças, é preciso salientar o fato comum às variedades do Português estudadas: a EL é bloqueada quando a primeira vogal for acentuada. Na literatura sobre o processo de resolução de encontro de núcleos silábicos, é comum a observação que a vogal acentuada não é apagada (cf. Nespor, 1987). Esse fato indica qual das vogais de uma seqüência analisada é eliminada pela regra de Apagamento do Elemento Extraviado (cf. análise de Bisol, 1996a). Portanto, nas duas variedades do Português, a EL consiste na eliminação da primeira vogal em uma cadeia vocálica que se delineia quando uma palavra que termina com vogal é seguida por outra que inicia com vogal. Estudos que comparam diferentes línguas apontam a elisão da primeira vogal como sendo o resultado mais comum trans-lingüisticamente, embora também seja atestada a eliminação da segunda vogal de uma seqüência de duas (cf. generalizações translingüísticas feitas por Casali, 1997). ${ }^{11}$

Um ponto importante a ser discutido quando da comparação entre diversas línguas é a direção da aplicação da EL. Casali (1997) atenta para o fato de as línguas apresentarem fenômenos sincrônicos e diacrônicos que sugerem a tendência em preservar segmentos na posição de início de palavra. Um desses fenômenos freqüentes em várias línguas, inclusive em Português, é a manutenção de contrastes no início de palavra em oposição à neutralização que é permitida em outras posições. ${ }^{12}$ Isso sinaliza a existência de uma assimetria entre as posições na palavra de modo que se espera uma maior proeminência acústica no início de palavra o que leva à preservação dos elementos nesse contexto. Essas considerações de Casali (1997), remontam à noção de Trubetzkoy (1939) segundo a qual certas posições proeminentes são mais propícias a manter contrastes entre tipos particulares de traços e/ou segmentos. Estaria aí a motivação para a preferência, nas duas variedades do Português, pela preservação da segunda vogal de uma seqüência vocálica e a conseqüente eliminação da primeira vogal prosodicamente mais fraca. Essa configuração sugere que a direção da aplicação da EL é da esquerda para a direita em PB e em PE.

Ainda em se tratando da seqüência de vogal tônica seguida de átona, observam-se resultados diferentes quando a seqüência for de vogais iguais. Enquanto em PE sempre o acento na primeira vogal leva ao bloqueio da DG, em PB esse acento não bloqueia a DG. Como discutido por Tenani (2002), 
esse fato também pode ser interpretado como índice da atuação do princípio de ressilabificação desencadeado pelo sândi. Segundo esse princípio, a direção da ressilabificação é da esquerda para a direita e, desse modo, quando o acento está à esquerda na seqüência, como em (9), a DG não é bloqueada. É importante salientar que a DG se aplica mesmo quando a primeira vogal acentuada é o elemento mais proeminente de $\phi$, como se observa em (9.2), e inclusive quando a aplicação da DG resulta em uma adjacência de acentos de $\phi_{s}$, como exemplificado em (9.2.i). Esse dado sugere que a DG não afeta, nesse contexto, a proeminência de $\phi$.

(9)

1.i. [o maraJ $\underline{a}$ a Folto] $\phi$

1.ii. [o marajé a a fricano] $\phi$

2.i. [o maras $\underline{\text { á}} \phi \phi$ [ạceIta]

2.ii. [o marajá] $\phi$ [apanHou]

3.i. [o marajá] $\phi$ [ạpenas aceitou]

3.ii. [o maraj $\underline{\underline{\alpha}}$ ] $\phi$ [apanhou sempre]

4.i. [o marajú] $I$ [äPós o conflito]

4.ii. [o maraj̦ $I$ [appesar da confusão]

maraj[a]foito
maraj[a]fricano
maraj[a]ceita
maraj[a]panhou
maraj[a]penas
maraj[a]panhou
maraj[a]pós
maraj[a]pesar

Em PE, a DG também é bloqueada quando a segunda vogal for acentuada. Portanto, em PE, a DG sempre é bloqueada quando uma das vogais for acentuada, independentemente da localização do acento (isto é, se o acento ocorre na primeira ou na segunda vogal da seqüência), do número de sílabas entre os acentos, ou do tipo de estrutura prosódica. Esses achados de Frota (1998: 79), obtidos a partir de exemplos como em (10), ${ }^{13}$ revelam que vogais acentuadas não sofrem DG. Esse fato em $\mathrm{PE}$ não depende do status do acento (ou seja, se é acento de $\omega$, como em 10.1, ou de $\phi$, como em 10.2), nem de uma restrição em evitar o choque de acentos (ou seja, o bloqueio ocorre quando há choque de acentos, como em 10.i, e também quando há uma sílaba entre os acentos, como em 10.ii). ${ }^{14}$ Segundo a pesquisadora portuguesa, 'this means that the importance of the stress status of any of the vowel bleeds the action of any rhytmical contraint due to chash avoidance' (p. 90).

(10)

1.i. [a caneta $\underline{\hat{A} m b a r}] \phi$

2.i. [o gaL $\underline{\underline{\alpha}}$ aForto] $\phi$

3.i. [a aLuna] $\phi[\underline{\mathrm{A}} \mathrm{ma}]$

4.i. [o gaL $\underline{\tilde{a}}] \phi$ [ạpanha]

5.i. [a aLuna] $I[$ [antes de partir] $] I$ ii. [a TÁbula $\underline{a} \mathrm{~A} M b a r] \phi$

ii. [o gaL立 africano] $\phi$

ii. [a astróloga] $\phi$ [äma]

ii. [o gaLẫ] $\phi$ [ạpaNHOU]

ii. [a astróloga $] I$ [
Diferentemente do PE, em que sempre há bloqueio da DG quando a segunda vogal é acentuada, em PB o bloqueio ocorre apenas quando o acento for interpretado como do domínio $\phi$, como ilustram (11.1) e (11.2). Vale lembrar que em Tenani (2002) são apresentadas medidas de duração do intervalo vocálico que constituem evidências de que a distância de uma a duas sílabas entre os acentos, nesses dois contextos, não é relevante para explicar o bloqueio da DG, pois mesmo quando os acentos não estão adjacentes o bloqueio ocorre. Por outro lado, quando a proeminência de $\phi$ não coincide com a sílaba candidata à DG, como em (11.3) e (11.4), o processo não é bloqueado independentemente da proximidade entre os acentos das palavras (cf. 11.3.i versus 11.3.ii).

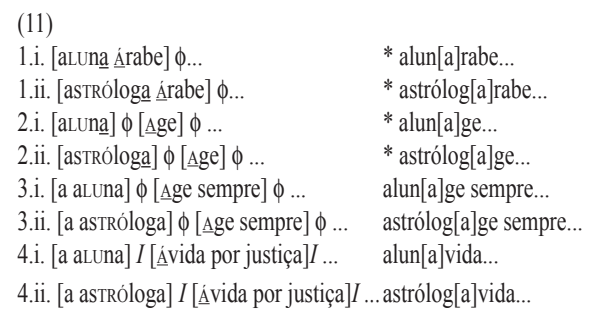

Esse contraste entre $\mathrm{PB}$ e PE quanto ao bloqueio da DG remete-nos ao contraste entre Grego e Italiano apontado por Nespor (1987). Em Grego, a DG é bloqueada caso o resultado da aplicação gerar um choque de acentos. Em Italiano, a DG se implementa mesmo quando o resultado for um choque de acentos. Embora nas duas línguas exista a tendência em evitar o choque de acentos, a diferença entre elas se verifica nas estratégias de que dispõem para minimizar um possível efeito de dissonância rítmica. Antes de tratarmos dessas estratégias, faz-se necessário completar o quadro comparativo entre as duas variedades do Português quanto ao bloqueio do sândi vocálico.

Um quadro semelhante ao bloqueio da DG em PB é o bloqueio da EL em PE. Em PE, quando a segunda vogal é acentuada em seqüências de vogais diferentes, a EL é sempre bloqueada em um mesmo $\phi$, como ilustra (12.1), mas entre $\phi_{\mathrm{s}}$ a EL é bloqueada somente quando o acento da vogal for também o acento de $\phi$ (cf. 12.2 versus 12.3). Também entre $I_{\mathrm{s}} \mathrm{a}$ EL não é bloqueada, como ilustra (12.4). Por outro lado, a DT é sempre permitida em um mesmo $\phi$, entre $I_{\mathrm{s}}$ e entre $\phi_{\mathrm{s}}$, exceto quando os acentos de $\phi$ estão muito próximos, como em (12.2.i). 
(12)

1.i. [o pútpito âMbar] $\phi$

1.ii. [0 vesTido $\underline{\mathrm{A}} \mathrm{Mbar}] \phi$

2.i. [0 dançarino] $\phi[\underline{A} \mathrm{ma}] \phi \ldots$

2.ii. [0 Músico $] \phi[\underline{\mathrm{A} m a}] \phi \ldots .$.

3.i. [o bailarino $] \phi[$ anda sempre $] \phi$...

3.ii. [0 Músico] $\phi$ [ANda sempre] $\phi . .$.

4.i. [0 bailarino] $][$ a

4.ii. [0 Músico] $][$ [avtes de partir $] I$...

Segundo Frota (1998: 88), os contextos em que os processos de ressilabificação não se implementam são aqueles em que os resultados são configurações rítmicas mal-formadas, as quais não são resolvidas por meio de outras estratégias, ou seja, o bloqueio da EL se dá para serem evitadas configurações que são interpretadas na língua como choque de acentos. Por trás dessas restrições rítmicas, visíveis por meio do bloqueio do processo de resolução do encontro de núcleos vocálicos, dois fatores estão atuando: distância fonológica entre os acentos e a estrutura prosódica. A relação entre esses fatores é estabelecida por Frota a partir do arcabouço teórico da fonologia métrica proposto por Nespor \& Vogel (1986) e Nespor (1990).

Nesses trabalhos, são freqüentes duas configurações de choque acentual, as quais estão presentes em PE quando os acentos de duas palavras se encontram em um mesmo $\phi$, como em (12.1), ou entre $\phi_{\mathrm{s}}$, como em (12.2). A configuração de choque de acentos em PE é representada em (13). Em (13.1), é apresentada a proposta de Frota (1998: 90) para a configuração mínima em que os acentos estão próximos o suficiente para resultar em um efeito de choque em PE. ${ }^{15}$ Dada essa configuração, é esperado o bloqueio da ditongação em todos os contextos em (12.1). O mesmo efeito de choque é esperado em (12.2) e (12.3), quando pelo menos um dos acentos envolvidos é o elemento proeminente de algum domínio prosódico mais alto que $\omega$, o que configura um padrão de choque de acentos no nível de $\phi$, como representado em (13.2).

(13)

1. Choque de acentos no nível mais baixo

\begin{tabular}{|lllll|}
\hline$\omega$ & $*$ & & & $*$ \\
$\Sigma$ & $*$ & & & $*$ \\
$\sigma$ & $*$ & & $(*)$ & $*$ \\
\hline
\end{tabular}

2. Choque de acentos no nível mais alto

\begin{tabular}{|llll|llll|}
\hline a. & & & & b. & & & \\
$\phi$ & $*$ & & $*$ & $\phi$ & $*$ & & \\
$\omega$ & $*$ & & $*$ & $\omega$ & $*$ & & $*$ \\
$\Sigma$ & $*$ & & $*$ & $\Sigma$ & $*$ & & $*$ \\
$\sigma$ & $*$ & $(*)$ & $*$ & $\sigma$ & $*$ & $(*)$ & $*$ \\
\hline
\end{tabular}

Essas expectativas de Frota não são confirmadas pelos resultados, porém a autora argumenta que a ditongação, diferentemente da elisão, resulta em uma distância fonológica suficiente entre os acentos dentro de $\phi$. Por essa razão, sempre se observam ditongos como resultado do encontro de núcleos silábicos nesse nível prosódico (cf. 12.1). Mas a distância que a ditongação proporciona não é suficiente para resolver o choque de acentos entre $\phi_{\mathrm{s}}$ (cf. 12.2), o que é uma evidência de que o efeito de choque de acentos nesse nível mais alto é maior do que dentro de $\phi$. Outra evidência de que a língua busca banir o choque de acentos no nível de $\phi$ é dada pelo contraste entre haver elisão quando a distância entre os acentos de $\phi$ no output é igual a três sílabas e haver o bloqueio quando a distância entre esses acentos é de duas sílabas (cf. 12.2 versus 12.3). A análise dos resultados da EL e da DT em PE leva Frota (1998: 91) a afirmar que o choque de acentos entre $\phi_{\mathrm{s}}$ é fortemente evitado, enquanto o choque dentro de $\phi$ é mais tolerado, provavelmente porque a língua tem outras estratégias para resolver o ‘choque mínimo' (cf. 13.1), mas não para o choque no nível mais alto (cf. 13.2).

Ainda a comparação entre (12.1) e (12.2), por um lado, e dessas com (12.3), por outro, sugere a existência de um 'directional head-effect', pois a elisão é sempre bloqueada quando o acento da vogal mais à direita coincidir com a cabeça de $\phi$ (cf. 12.1 e 12.2). Portanto, Frota (1998) constata que é importante não apenas o nível em que o choque de acentos ocorre, mas também o fato de a cabeça do domínio $\phi$ ser à direita. Ou seja, o choque entre os acentos de $\phi$ e de $\omega$ não bloqueia a EL, mas os choques entre os acentos de $\omega$ e de $\phi$ ou entre os acentos de dois $\phi_{\mathrm{s}}$ bloqueiam a EL em PE. A investigadora portuguesa ainda se pergunta se esse efeito da proeminência à direita também é relevante para o choque de acentos definido como o choque mínimo em PE (cf. 13.1). As estruturas exemplificadas em $(14)^{16}$ permitem verificar que a EL continua sendo bloqueada mesmo quando a segunda vogal da seqüência não mais coincide com a cabeça de $\phi$. Esses resultados revelam que a proeminência da cabeça à direita não é uma condição necessária para o choque de acentos seja evitado no nível mínimo definido para o $\mathrm{PE}$ e que, portanto, o 
bloqueio da elisão em um mesmo $\phi$ decorre de restrições rítmicas.

(14)

1. O último ânjo negro revoltou-se contra Deus. *últimanjo; últim[w]anjo

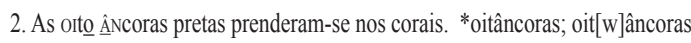

Como já apontado, quando a segunda vogal é acentuada, os contextos do bloqueio da EL em PE são iguais aos do bloqueio da DG em PB (cf. quadro 3). Tem-se aí um fato relevante em comum entre as duas variedades do Português: o bloqueio dos processos em que uma das vogais da cadeia vocálica é eliminada em um mesmo $\phi$ e entre $\phi_{\mathrm{s}}$, quando a distância entre os acentos do output é menor que duas sílabas.

Quadro 3. Bloqueio da DG em PB e da EL em PE

\begin{tabular}{|l|l|l|l|l|}
\cline { 2 - 5 } \multicolumn{1}{c|}{} & \multicolumn{2}{c|}{ DG / PB } & \multicolumn{2}{c|}{ EL / PE } \\
\hline Estrutura prosódica & $1 \sigma$ & $2 \sigma$ & $1 \sigma$ & $2 \sigma$ \\
\hline Mesmo $\phi$ & DG & DG & EL/DT & EL/DT \\
$\phi+\phi$ não-ramificado & DG & DG & EL/DT & EL/DT \\
$\phi+\phi$ ramificado & DG & DG & EL/DT & EL/DT \\
I+I & DG & DG & EL/DT & EL/DT \\
\hline
\end{tabular}

Onde: NEGRITO indica o bloqueio do processo; CAIXA ALTA indica a aplicação do processo; $1 \sigma$ e $2 \sigma$ indicam o número de sílabas entre os acentos.

Esse resultado da DG no PB também pode ser visto como decorrente de uma restrição rítmica semelhante à identificada em PE quando analisado o contexto do bloqueio da EL. Trilhando o caminho percorrido por Frota (1998) para o PE, dois níveis de choque acentual podem ser definidos para o $\mathrm{PB}$ : (i) o choque de acentos no nível mínimo, que envolve acentos de $\omega$ dentro de um mesmo $\phi$ (cf. 13.1); e (ii) o choque de acentos no nível mais alto, que envolve o acento de $\phi$ (cf. 13.2). Ao seguir essa interpretação, o bloqueio da DG em PB seria condicionado pela restrição rítmica em evitar a proximidade dos acentos dentro de $\phi$ e entre $\phi_{\mathrm{s}}$, quando o acento mais à direita for o proeminente de $\phi$. Em outras palavras, quando há choque entre os acentos de $\omega$ e de $\phi$ e entre os acentos de dois $\phi$, a DG é bloqueada; mas quando há choque entre os acentos de $\phi$ e de $\omega$ e entre os acentos de $\omega_{\mathrm{s}}$, a DG ocorre em PB.

Mas como em PE, faz-se necessário verificar o resultado do processo de sândi quando a segunda vogal acentuada não coincide com o elemento cabeça dentro de $\phi$. As estruturas que

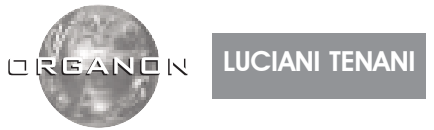

asseguram essa relação são exemplificadas em (15). ${ }^{17}$ Os resultados das medidas da duração do intervalo vocálico de /a+á/ confirmam que a DG se aplica quando a segunda vogal da seqüência não coincide com o elemento proeminente de $\phi$. Portanto, em PB, o bloqueio da DG dentro de $\phi$ não é condicionado por restrições rítmicas relacionadas ao choque de acentos no nível mínimo, mas por um princípio em assegurar a proeminência da cabeça de $\phi$.

(15)

1. [A Nova $\underline{\text { Árabe NEgra] } \phi}$ a nov[a]rabe negra

2. [A ÚLtima ́ㅏrabe NEgra] $\phi \quad$ a últim[a]rabe negra

A implementação da DG nos contextos em (15) é mais uma evidência a favor da interpretação proposta por Abaurre (1996) para o bloqueio da DG em PB. Para essa pesquisadora brasileira, o bloqueio da DG é evidência da importância da preservação da proeminência rítmica do acento de $\phi$, uma vez que esse bloqueio sempre se verifica quando a segunda vogal carrega a informação sobre a cabeça de $\phi$. Essa informação é de natureza sintática porque a proeminência de $\phi$ é definida a partir de uma hierarquia de proeminências sintaticamente motivadas (cf. algoritmo de formação de $\phi$ ). Como já argumentara Abaurre (1996), a proeminência relativa de $\phi$ sinaliza a direção da recursividade sintática nas línguas naturais e, como o Português é uma língua de recursividade à direita, o acento mais à direita tem valor forte em relação aos demais dentro de $\phi$. Portanto, a explicação para o bloqueio da DG em PB está na preservação da proeminência do acento que traz informação sobre a direção da recursividade sintática da língua.

Como $\mathrm{PE}$ não difere do $\mathrm{PB}$ quanto à direção da recursividade sintática, espera-se que em PE também o elemento mais à direta de $\phi$ seja preservado, pois esse elemento também traz uma informação sintática relevante para o PE. De fato, em PE também se observa a preservação da cabeça de $\phi$ quando analisados os contextos de bloqueio da EL. Frota (1998) argumenta a favor de um 'directional head-effect' visível apenas no domínio de $\phi$, mas não explora esse efeito. No entanto, em PE parece haver evidências, por meio do bloqueio da EL, de que existe uma restrição para preservar a proeminência que carrega a informação da direção da recursividade sintática à medida que, ao ser garantida a 
distância entre os acentos (sejam eles de $\omega$ ou de $\phi)$, é assegurada a proeminência da cabeça de $\phi$ em relação aos demais acentos adjacentes.

Entretanto, essa restrição rítmica que preserva a proeminência relativa de $\phi$ não é suficiente para explicar os resultados em PE. A análise do bloqueio da EL leva a pesquisadora portuguesa a trazer evidências que revelam que também estão em jogo restrições rítmicas que visam a evitar o choque de acentos tanto dentro de $\phi$ quanto entre $\phi_{\mathrm{s}}$ (cf. definição de choque de acentos em 13). Portanto, em PE, desvenda-se mais claramente uma relação entre o bloqueio de processos segmentais e restrições rítmicas que visam a evitar o choque de acentos. Em PB, essas restrições rítmicas não são identificáveis quando considerado o bloqueio da DG, mas são visíveis por meio do bloqueio da EL, como se argumenta a seguir.

Diferentemente dos resultados da EL em PE e da DG em PB são os resultados de bloqueio da EL encontrados em PB. Quando a segunda vogal é acentuada, como em (16), sempre a elisão da primeira vogal é bloqueada, exceto quando há espaço suficiente entre os acentos de $\phi$, como ilustra (16.3.ii). Por outro lado, esse choque dos núcleos silábicos resulta em um ditongo em todos os contextos.

\section{(16)}

1.i. [acuna útili] $\phi$

1.ii. [astrólogạ útili] $\phi$

2.i. [auuna] $\phi[\underline{\underline{u s a}}]$

2.ii. [astrólogạ] $\phi$ [usa]

3.i. [a aLuna] $\phi$ [usa sempre]

3.ii. [a astróloga] $\phi$ [usa sempre]

4.i. [a auuna] $I$ [ứtil mas desorganizada]

* alun[u]til; alun[aw]til

* astrólog[u]til; astrólog[aw]til

* alun[u]sa; alun[aw]sa

* astrólog[u]sa; astrólog[aw]sa

*alun[u]sa; alun[aw]sa

astrólog[u]sa; astrólog[aw]sa

4.ii. [a astróloga] $I$ [ứtil mas desorganizada] *astrólog[u]til; astrólog[aw]til

A análise dos contextos de bloqueio da elisão permite mais uma vez atestar a relevância da proeminência de $\phi$ para o PB. Em todos os contextos em (16.i), a elisão da vogal baixa resulta em um choque silábico, ou no nível de $\omega$ - como ilustra (17.1) - ou no de $\phi$ - como ilustra (17.2). Já em todos os contextos em (16.ii), a elisão da vogal não gera um choque de acentos em nenhum nível e, no entanto, a EL é bloqueada quando a distância entre os acentos do output é menor que três sílabas. Dessa maneira, somente em (16.3.ii) a aplicação da elisão é permitida e, assim, é preservada a distância de três sílabas entre os acentos de $\phi$, como se verifica em (17.3) e, conseqüentemente, é assegurada a proeminência de $\phi$.

\section{(17)}

1. [aLuna útil] $\phi$
\begin{tabular}{|llllll|}
\hline$\phi$ & & & & $*$ & \\
$\mathrm{C}=\omega$ & & $*$ & & $*$ & \\
$\Sigma$ & & $*$ & & $*$ & \\
$\sigma$ & $*$ & $*$ & $(*)$ & $*$ & $*$ \\
& $\mathrm{a}$ & $\mathrm{lu}$ & $\mathrm{Na}$ & $\mathrm{u}$ & til \\
\hline
\end{tabular}

1. [aluna $] \phi[\underline{\text { usa }} \phi \phi$
\begin{tabular}{|llllll|}
\hline $\mathrm{C}=\omega$ & & $*$ & & $*$ & \\
$\Sigma$ & & $*$ & & $*$ & \\
$\sigma$ & $*$ & $*$ & $(*)$ & $*$ & $*$ \\
& $\mathrm{a}$ & $\mathrm{lu}$ & $\mathrm{na}$ & $\mathrm{u}$ & $\mathrm{sa}$ \\
\hline
\end{tabular}

3. [astróloga $] \phi$ [usa SEMpre] $\phi$

\begin{tabular}{|lllllllll|}
\hline$\phi$ & & $*$ & & & & & $*$ & \\
$\mathrm{C}=\omega$ & & $*$ & & & $*$ & & $*$ & \\
$\Sigma$ & & $*$ & & & $*$ & & $*$ & \\
$\sigma$ & $*$ & $*$ & $*$ & $(*)$ & $*$ & $*$ & $*$ & $*$ \\
& as & tró & lo & ga & u & sa & sem & sere \\
\hline
\end{tabular}

Mas, diferentemente do que ocorre com a DG, há o bloqueio da EL quando a segunda vogal acentuada não coincide com o elemento cabeça dentro de $\phi$, como ilustra (18). O resultado apresentado em (18) revela que há um efeito de choque de acentos no nível mais baixo, como definido em (13.1). Portanto, em PB, o bloqueio da EL dentro de $\phi$ é condicionado por restrições rítmicas relacionadas ao choque de acentos no nível mínimo que envolve o acento de $\omega$.

(18)

1. [A Nova ursa BRANca] $\phi \quad$ *a nov[u]rsa branca; a nov[aw]rsa

2. [A út tima ursa BRANca] $\phi \quad * a$ últim[u]rsa branca; a últim[aw]rsa

Observa-se que em todos os contextos, sempre é permitida a ditongação, o que constitui uma evidência de que esse processo de otimização da cadeia silábica gera um resultado que garante uma distância fonologicamente suficiente entre os acentos em um mesmo $\phi$ e entre $\phi_{\mathrm{s}}$, minimizando o efeito de 'dissonância rítmica'. Nota-se que esse mesmo papel da ditongação foi constatado por Frota (1998: 90) ao analisar os mesmos contextos prosódicos no PE. A diferença encontra-se, porém, no fato de em PE a ditongação não produzir uma distância fonologicamente suficiente entre os acentos de $\phi$, pois nesse contexto também é bloqueada a ditongação, mantendo-se as vogais 
separadas. Isso se deve à maior sensibilidade do PE em evitar o choque de acentos entre $\phi_{\mathrm{s}}$, como já mostrado por meio das grades métricas em (13). Em PB, o bloqueio da EL também decorre de uma restrição rítmica em evitar um efeito de choque de acentos de palavras prosódicas (indicada por $\omega$ ). No entanto, essa restrição não é suficiente para explicar os resultados para a DG. Quando há encontro de núcleos silábicos preenchidos por vogais iguais, verifica-se em $\mathrm{PB}$ um princípio em preservar o elemento mais proeminente de $\phi$. Em PE, esse princípio não é visível, pois, conforme argumentação feita por Frota (1998), as restrições rítmicas visam a evitar o choque acentual.

Por fim, a análise do contexto em que no input os acentos estão adjacentes revela mais uma vez semelhanças e diferenças entre as duas variedades do Português quanto à estratégia de resolução do choque de acentos.

Considerando as medidas de duração dos intervalos vocálicos /á+á/ nas quatro fronteiras prosódicas investigadas (cf. 7), ${ }^{18}$ encontram-se evidências a favor da interpretação de que, no PB, uma das estratégias para resolução do choque de acentos é a inserção de batida rítmica dentro de $\phi$ e entre $\phi_{\mathrm{s}}$. Na literatura, encontra-se a afirmação de que a retração do acento dentro de $\phi$ também ocorre (cf. Abousalh, 1997; Sândalo \& Truckenbrodt, 2002). Em Tenani (2004), é apresentada uma análise da variação de altura tonal de dados experimentais que não trazem evidência de haver diferença de altura tonal que possa ser interpretada como uma estratégia de resolução de choque acentual.

No PB, há evidências de sempre ser resolvido o choque de acentos tanto no nível mínimo (choque de acentos dentro de $\phi$ ) quanto no nível mais alto (choque de acentos entre $\phi_{\mathrm{s}}$ ). No PE, Frota (1998) mostra que apenas o choque de acentos dentro de $\phi$ é solucionado e que quando há uma fronteira de $\phi$ entre os acentos nenhuma estratégia se observa. No quadro abaixo, visualizam-se as diferenças entre PB e PE quanto às estratégias de resolução de choque acentual mencionadas.

Quadro 4. Estratégias de resolução de choque acentual em $P B$ e PE

\begin{tabular}{|lcc|}
\hline Diferença de altura tonal & $\mathrm{PB}$ & $\mathrm{PE}$ \\
Retração do acento dentro de $\phi$ & $\mathbf{x}$ & $\mathbf{x}$ \\
Inserção de batida rítmica dentro de $\phi$ & $\checkmark$ & $\boldsymbol{x}$ \\
Inserção de batida rítmica entre $\phi_{\mathrm{s}}$ & $\checkmark$ & $\mathbf{x}$ \\
\hline
\end{tabular}

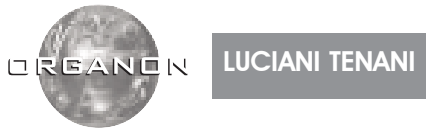

Exceto a ausência da estratégia de resolução de configurações rítmicas mal-formadas por meio de diferenças na altura tonal, as duas variedades do Português diferem entre si quanto às estratégias disponíveis para solucionar o choque de acentos dentro de $\phi$ e quanto à avaliação de em que nível o choque de acentos gera perturbações rítmicas.

A ausência de uma estratégia de resolução de choque de acentos entre $\phi_{\mathrm{s}}$ em PE é interpretada por Frota (1998: 127) com base na distinção crucial entre o nível mínimo e o mais alto em que ocorre o choque de acentos como sendo evidência de que o PE figura "as an extreme case of the weaker enforcement of rhythmic alternation by grid means that characterises the level(s) above the minimal clash level".

Com base em nossos resultados, o PB não é um caso extremo semelhante ao PE e, como o Inglês e o Italiano, dispõe de regras de ajustes rítmicos tanto no nível mínimo quanto no nível mais alto (cf. 13). Vale notar que no PB duas estratégias operam para resolver o choque no nível mínimo e, no PE, apenas uma. Essas diferenças no que diz respeito às estratégias de resolução de configurações rítmicas mal-formadas contribuem para que haja diferenças rítmicas entre essas duas variedades do Português.

\section{COMPARANDO PB E PE}

A comparação dos resultados obtidos segundo a mesma metodologia e considerando-se os mesmos contextos prosódicos de Frota (1998) propicia a identificação das semelhanças e diferenças entre o PB e o PE quanto ao bloqueio do sândi vocálico. Resumidamente, pode-se afirmar que, em PB, existe um efeito de direcionalidade esquerda/direita na medida em que apenas o acento mais à direita do domínio $\phi$ bloqueia o processo da DG. Esse mesmo efeito é identificado em PE quando é analisado o bloqueio da EL e da DT. Outro ponto em comum é que se verifica a atuação de uma restrição rítmica em evitar choque de acentos dentro de $\phi$. Essa restrição é visível em PB quando analisados os contextos de bloqueio da EL e, em PE, os contextos da DG. Portanto, nas duas variedades do Português, há restrições rítmicas que bloqueiam a configuração de estruturas rítmicas mal-formadas e há um efeito de direcionalidade esquerda/direita que decorre de uma restrição que preserva a proeminência do acento mais à direita de $\phi$. 


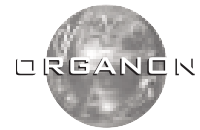

Outra semelhança entre as duas variedades do Português é que as restrições que operam em cada variedade dependem do tipo do processo envolvido e da estrutura prosódica que as contém. No entanto, o que diferencia PB do PE não é o papel da proeminência do domínio prosódico relevante para a aplicação das restrições rítmicas, que é o domínio $\phi$, mas o fato de um mesmo processo segmental ter comportamento diferente em cada variedade.

Quando considerados os contextos em que o choque de acentos se configura já no input, outra diferença se verifica no que concerne às estratégias de resolução dos efeitos de choque acentual. Enquanto PB lança mão de duas estratégias para solucionar o choque de acentos dentro de $\phi, \mathrm{PE}$ dispõe de apenas uma estratégia. Enquanto PB recorre à estratégia de inserção de batida rítmica para resolver a adjacência de acentos de $\phi$, o PE não ajusta essa configuração em que as proeminências rítmicas não se alteram.

Esse quadro parece dar sustentação às percepções de brasileiros sobre o ritmo do PE. Para falantes da variedade brasileira do Português, há 'muitos acentos' na variedade européia, o que acaba por dificultar a compreensão dos enunciados portugueses. O que parece estar em jogo é que as seqüências em que o PE admite a adjacência de acentos entre $\phi_{\mathrm{s}}$ são, pelos falantes de PB, percebidos como 'clusters rítmicos', como configurações malformadas. Concluímos este texto tendo apresentado evidências rítmicas - por meio da análise de dados de bloqueio do sândi vocálico - de que o domínio $\phi$ é ativo nas duas variedades estudadas do Português.

\section{REFERÊNCIAS BIBLIOGRÁFICAS}

ABAURRE, M. B. M. Acento frasal e processos fonológicos segmentais. Letras de Hoje, Porto Alegre, v.2, n.31, p. 41-50, 1996.

ABOUSALH, E. F. Resolução de choques de acento no português brasileiro. 1997, 157p. Dissertação (Mestrado) - Instituto de Estudos da Linguagem, Universidade Estadual de Campinas, Campinas.

BISOL, L. Sândi vocálico externo: degeminação e elisão. Cadernos de Estudos Lingüísticos, Campinas, n. 23, p. 83-101, 1992.

Sândi vocálico externo. In: ILARI, R. (Org.) Gramática do Português Falado II. Campinas: Editora da Unicamp, 1993, p. 21-38.
. Sândi externo: o processo e a variação. In: KATO, M. (Org.) Gramática do Português Falado V. Campinas: Editora da Unicamp, 1996a, p. 55-96. . O sândi e a ressilabação. Letras de Hoje, Porto Alegre, n. 31 (2), p. 159-168, 1996 b. . A elisão, uma regra variável. Letras de Hoje, Porto Alegre, n. 35 (1), p. 319-330, 2000.

CASALI, R. F. Vowel elision in hiatus contexts: which vowel goes? Language, Washington, v. 73, n. 3; p. 493-533, 1997.

CINQUE, G. A null theory of phrases and compound stress. Linguistic Inquiry, Cambridge, Massachusetts, v. 24, n. 2, p. 239-297, 1993.

FROTA, S. Prosody and Focus in European Portuguese. 1998, 385p. Tese (Doutorado). Faculdade de Letras, Universidade de Lisboa, Lisboa. Publicado por Garland Publishing (Outstanding Dissertations on Linguistics). New York/London, 2000.

HAYES, B. Metrical Stress Theory: principles and case studies. Ms, 1991.

NESPOR, M. Vowel degemination and fast speech rules. Phonology Yearbook 4, Cambridge, 1987. p. 61-85.

. On the separation of prosodic and rhythmic phonology. In: INKELAS, S.; ZEC, D. The phonology-syntax conncection. Chicago: Chicago University Press, 1990, p. 243-258. 1994.

Setting parameters at a prelexical stage. Ms, NESPOR, M.; VOGEL, I. Prosodic Phonology. Dordrecht-Holland: Foris Publications, 1986.

SANDALO, F.; TRUCKENBRODT, H. Some notes on phonological phrasing in Brazilian Portuguese. The MIT Working papers, v. 42. Cambridge: The MIT Press, 2002.

SELKIRK, E. O. Phonology and syntax, the relation between sound and structure. Cambridge: Cambridge University Press, 1984.

TENANI, L. Análise Prosódica de Inserções Parentéticas no Corpus da Gramática do Português Falado (PGPF). Sínteses, Campinas, v. 2, p. $397-$ 407, 1997.

. Domínios prosódicos no Português do Brasil: implicações para a prosódia e para a aplicação de processos fonológicos, 2002. 317p. Tese (Doutorado) - Instituto de Estudos da Linguagem, Universidade Estadual de Campinas, Campinas.

Haplologia e domínios prosódicos. Letras de Hoje, Porto Alegre, v. 4, n. 38, p. 283-306, 2003. 
. A importância da proeminência da frase fonológica no Português Brasileiro. Revista de Estudos da Linguagem, Belo Horizonte, v. 12, n. 2, p. 289-318, 2004 .

TRUBETZKOY, N. S. Principles of phonology. Berkeley, Los Angeles: University of California Press, 1939.

\section{Notas:}

${ }^{1}$ Lembramos que o acento também bloqueia a haplologia quando a primeira sílaba da seqüência de duas for acentuada ou quando ambas as sílabas forem acentuadas (cf. Tenani, 2003). Faz-se necessário, porém, pesquisar mais detalhadamente a haplologia para se saber os contextos (segmentais e morfofonológicos) que bloqueiam esse processo. Por essa razão, não consideramos a haplologia neste texto.

${ }^{2}$ Mantivemos os mesmos exemplos de Bisol (1993).

${ }^{3}$ A relação entre esses dois fatores é estabelecida, segundo essa abordagem teórica, nos seguintes termos: "rhythm is represented (...) in terms of the grid, which is constructed on the basis of information contained in the prosodic tree. That is, each syllable is assigned one position, marked by an $x$ on the first grid level. Subsequently, the DTE (designated terminal element) of each higher prosodic category (excluding [...] the clitic group), is assigned one additional $x$ on a separate grid level" (Nespor, 1990: 245)

${ }^{4}$ Considerações a respeito dessas restrições encontram-se em Tenani (2002).

${ }^{5}$ A maioria das sentenças é elaborada com base no corpus construído por Frota (1998) para o PE, porém as sentenças não são exatamente iguais ao do PE por ter sido necessário fazer algumas adaptações para o PB.

${ }^{6}$ Os valores da duração encontrados para o intervalo vocálico / $\mathrm{a}+\mathrm{a} / \mathrm{em}$ ' $\underline{a} \underline{a}$ luna' nos levam a afirmar que houve a DG nesse contexto. Isso não implica afirmar que não haja distinção em PB entre 'a aluna' e 'aluna' quando considerados enunciados como: 'a aluna árabe pagou meia entrada' e 'aluna árabe paga meia entrada'.

${ }^{7}$ Cf. em Tenani (1997) uma análise das características prosódicas dos parênteses em $\mathrm{PB}$.

${ }^{8}$ Vale lembrar que em Tenani (2002) se mostra que o acento de palavra ou de níveis superiores a esse domínio não bloqueia o vozeamento da fricativa ou o tapping, mas bloqueia a haplologia quando a primeira sílaba for a acentuada.

${ }^{9}$ No quadro está sendo considerada a seqüência $/ \mathrm{a}+\mathrm{u} / \mathrm{em} \mathrm{PB}$, a seqüência /u+á/ em PE.

${ }^{10} \mathrm{Em} \mathrm{PB}$, a presença da vogal baixa /a/ na segunda posição da seqüência preferencialmente resulta em um ditongo decrescente (cf. Bisol, 1993, 1996a).

${ }^{11}$ Agradeço à Sonia Frota, Universidade de Lisboa, e à Marina Vigário, Universidade do Minho, por terem me chamado a atenção para essa discussão.

${ }^{12} \mathrm{Na}$ literatura sobre o PB e o PE há registro de haver grande neutralização das oposições entre as vogais quando essas se encontram em posição átona final de palavra. Dos sete fonemas vocálicos do Português, passa-se a apenas três nessa posição. ${ }^{13}$ Os exemplos dados em (10) são os apresentados por Frota (1998: 79, 39).

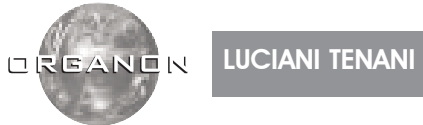

${ }^{14}$ Vale observar que em PE são consideradas vogais orais e nasais.

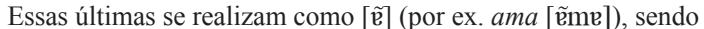
semelhantes às vogais orais átonas [p] (por ex. aluna [rlune]). Em PB, em uma seqüência de vogal oral - vogal nasal também é passível de sofrer sândi (por ex. casa antiga ca[zã]tiga), porém isso não se verifica quando a vogal nasal ocupar a primeira posição na seqüência vocálica (por ex. maçã amarela *ma[sã]marela). Nesse segundo contexto segmental, o bloqueio do processo se dá em razão do traço de nasalidade. Por essa razão, sempre foram consideradas vogais orais em $\mathrm{PB}$.

${ }^{15}$ Para Frota (1998: 89), o bloqueio da EL dentro de $\phi$ mesmo quando o output apresenta uma sílaba átona entre os acentos de palavra (cf. 12.1.ii) é evidência de que essa distância não é suficiente para minimizar o efeito de choque de acentos dentro desse domínio.

${ }^{16}$ Em Frota (1998: 92) esses são os exemplos (52).

${ }^{17}$ As sentenças analisadas foram 'a nova árabe negra recebeu o tratamento na festa', 'a última árabe negra recebeu o tratamento na festa'. E as medidas de duração do intervalo vocálico foram comparadas com as medidas dos demais contextos estudados para confirmar a DG.

${ }^{18}$ Uma discussão acerca da interpretação das medidas de duração do intervalo vocálico como evidência de inserção de batida rítmica é feita em Tenani (2002). 